\title{
New Anesthetic Technique for Dacryocystorhinostomy: 218 Cases with Local-Anesthesia Ultrasonographic Guided and Blunt Cannula
}

\author{
Hugo C. T. Siqueira ${ }^{1,2 *}$, Clarissa M. M. Stoffel de Siqueira ${ }^{3}$, Marlon Miguel Bianchi de Lima3, \\ Leonardo T. C. Lins ${ }^{4,5}$ \\ ${ }^{1}$ Department of Anesthesiology, Centro de Estudos e Pesquisas Oculistas Associados (CEPOA), \\ Rio de Janeiro, Brazil \\ ${ }^{2}$ Department of Anesthesiology, Hospital do Olho (HO) Julio Candido de Brito, Duque de Caxias, Brazil \\ ${ }^{3}$ Department of Ophthalmology, Centro de Estudos e Pesquisas Oculistas Associados (CEPOA), Rio de Janeiro, Brazil \\ ${ }^{4}$ Department of Oculoplastics, Centro de Estudos e Pesquisas Oculistas Associados (CEPOA), Rio de Janeiro, Brazil \\ ${ }^{5}$ Hospital do Olho (HO) Julio Candido de Brito, Duque de Caxias, Brazil \\ Email: *hugosiqueira@yahoo.com.br
}

How to cite this paper: Siqueira, H.C.T., de Siqueira, C.M.M.S., de Lima, M.M.B. and Lins, L.T.C. (2021) New Anesthetic Technique for Dacryocystorhinostomy: 218 Cases with Local-Anesthesia Ultrasonographic Guided and Blunt Cannula. Open Journal of Ophthalmology, 11, 282-292. https://doi.org/10.4236/ojoph.2021.114023

Received: August 27, 2021

Accepted: November 13, 2021

Published: November 16, 2021

Copyright $\odot 2021$ by author(s) and Scientific Research Publishing Inc. This work is licensed under the Creative Commons Attribution International License (CC BY 4.0).

http://creativecommons.org/licenses/by/4.0/ (c) (i) Open Access

\begin{abstract}
Introduction: Epiphora is a common ophthalmologic complaint and referrals to oculoplastics and, in the presence of lower complete lacrimonasal duct obstruction, may lead to mild to severe complications, thus requiring surgery to create a new drainage path. The external dacryocystorhinostomy with silicon intubation is the surgical technique with better long-term outcomes and performed in the institutions where this study was conducted. Can be performed under either general or loco-regional anesthesia, or a combination of both. Methods: This article presents a revision of 218 consecutive cases from December 2016 to June 2021 in two specialized centers with the same standardized surgical and anesthetic technique. Results: 242 surgical prontuaries were selected, with 218 filling the inclusion criteria. $13 \%$ of the patients required additional anesthetic infusion before the beginning of the surgery; $2.7 \%$ of the patients required field anesthetic infusion during the surgery and $6.4 \%$ required supplementary sedation, thus meaning a positive outcome, as the number of patients with intraoperative complaints was low, and the overall comfort was high. During the follow up, no patient required pain medication after 24 hours. Discussion: This study points towards the feasibility of the described technique in an outpatient fashion, with low, mild and tolerable side effects associated.
\end{abstract}




\section{Keywords}

Dacryocystorhinostomy, Local Anesthesia, Ultrasound

\section{Introduction}

Epiphora, or excessive lacrimonasal drainage is one of the most common ophthalmologic symptoms that leads to referrals to oculoplastics clinic for evaluation [1]. When caused by lower complete lacrimonasal duct obstruction, may be the initial presentation of a set of consequential events that can lead to dacryocystitis, abscess, fistulas, or, in extreme cases, meningoencefalitis [2] [3]. The origin of the obstruction may be congenital or acquired and, in order to be corrected, the most successful method is surgically made [4] [5]. Amongst several techniques, the external dacryocystorhinostomy (ED) with silicon intubation is still the one with the best outcomes and majority of studies so far [6] [7].

This surgery can be performed under general anesthesia, loco-regional or with a combination of both techniques. The ideal technique should achieve minimum bleeding rate, hospitalization time and require minimum post-operative analgesic compsumation [8] [9].

Loco-regional anesthesia is well stablished in adult population and is associated with less bleeding rate, hospitalization time and post-operative analgesic compsumation [8]. However, there is no effective padronized technique. After bibliographic consultation, it was proposed that the nerve territories that should be blocked to ensure adequate anesthesia would be nasocilliary, supra-trochlear, infra-trochlear, supra-orbitary and infra-orbitary [9] [10] [11] [12]. Each blockage territory is described individually for special situations, and also its ultrasound guidance, however, until june 2021 there were no studies combining these techniques for ED. In order to avoid minor hemorrhagic complications, it was proposed utilization of a sterile blunt cannula $25 \mathrm{G} \times 38 \mathrm{~mm}$.

Therefore, the padronized blockage was ultrasound guided of nasocilliary, supra-trochlear, infra-trochlear, supra-orbitary and infra-orbitary nerves, with the utilization of the above described blunt cannula. This prontuary revision accounts for 218 consecutive ED cases with the detailed description of this technique, adverse events and outcomes.

\section{Methods}

\subsection{Methodology}

This study was conducted in the archives section of Centro de Estudos e Pesquisas Oculistas Associados, Rio de Janeiro, RJ, Brazil, and Hospital do Olho Julio Candido de Brito, Duque de Caxias, RJ, Brazil. IRB from both institutions stated that this work adhered to the tenets of the Declaration of Helsinki. In July 2021, research was performed in the archives of both institutions participating in the presenting study and it was selected surgical prontuaries of 242 patients submit- 
ted to ED from December 2016 to June 2021. After verification of eligibility criteria, 24 were excluded. The remaining 218, were suited to evaluation and enrolled the study. It was utilized as inclusion criteria: complete prontuaries from patients above 18 years of age, submitted to ED under both same padronized surgical and anesthesia technique, where it could be retrieved the following data: surgery date, gender and age, initial anesthetic volume bolus (IAV), final anesthetic volume (FAV), initial sedation (IS), supplementary sedation required (SS) and analgesic consumption in the same day (AC1), $24 \mathrm{~h}$ after (AC2), 07 days after (AC3) and 30 days after (AC4), time (minutes) to hospitalar discharge and possible adverse events (tables 01 and 02 ). As exclusion criteria it was utilized: patients under 18 years of age and incomplete data. Padronized anesthesia technique in figs. 01 and 02 . Before engaging the surgery all submitted patients were asked to sign a consent form stating fully awareness of both anesthetic and surgical process, with possible side effects and outcomes, along with authorization for publishing the results, with the due protection of their identities. Padronized anesthetic technique as follows:

All patients in supine position. It was utilized sterile $25 \mathrm{G} \times 38 \mathrm{~mm}$ blunt cannula and Mobissom ${ }^{\circledR} \mathrm{M} 4$ wireless ultrasound $10-14 \mathrm{MHz}$, set to depth at 2 $5 \mathrm{~cm}$ and a solution of Levobupivacaine $0.75 \%$ with hialuronidasis at $15 \mathrm{IU} / \mathrm{mL}$. All patients had a 2\% lidocaine and 1:200.000 adrenaline soaked gauze positioned in the middle nasal meatus.

\subsection{Technique}

Nasociliary nerve: cannula insertion must be above or bellow the caruncula, but not through, to avoid damage to its structure, and must be inserted with all range; positioning of USG probe is at ocular transversal nine hour cut; USG set with low gain image shows, from the most anterior to the most posterior image, ocular globe, rectus medialis sheet and orbitary medial wall. Cannula should be observed in parallel with USG surface, within the orbitary structures, close to eye globe. The anesthetic solution infusion can be observed as a rising hypoechoic structure pushing the surroundings from posterior and medial to the opposite direction. At this site, 2.5 to $4 \mathrm{~mL}$ can be infused.

Supraorbitary nerve: arises from supraorbitary notch, identified by surface anatomy and marked with hydrophilic surgical marker. A small incision made with a insulin needle may be necessary to pass the cannula through the skin; USG probe positioning is against superior orbitary crest, with focus on previously made mark of assumed position of supraorbitary notch; USG image shows, from anterior to posterior, skin, subcutaneous tissue and frontal bone periosteum. Supraorbitary notch can be visualized as a continuity fail in the periosteum, where the supraorbitary nerve arises from. Anesthetic solution injection can be visualized as a rising hypoechogenic structure pushing the surroundings from posterior to anterior, and the cannula can be visualized as a hyperechogenic structure. The angulation that the cannula can be inserted may vary 
from 90 to 180 degrees, depending on hand angulation and USG visualization. At this site, 0.5 to $1.0 \mathrm{~mL}$ can be infused.

Supratrochlear and infratrochlear nerves: after localization of the supero-medial orbitary angle, a small skin incision can be made with an insulin needle, and, thereafter, the cannula can be inserted towards the lacrimonasal crest, located profound to the medial cantal tendon; USG probe positioning is towards the medial cantal tendon; USG image, from anterior to posterior, shows skin, subcutaneous tissue, the medial cantal tendon and the caruncula, and periosteum adjacent to the tendon. The tip of the cannula must be located between the tendon and the periosteum. Anesthetic infusion must cause a tissue movement towards both superior and inferior directions from the structures around the medial cantal tendon. At this site, 2.5 to $3.5 \mathrm{~mL}$ of anesthetic solution can be infused

Infraorbitary nerve: arises from infraorbitary foramen, located in the maxillary bone, circa $1 \mathrm{~cm}$ bellow the infraorbitary notch; identified by surface anatomy as a plateau and marked with hydrophilic pen. After a small skin incision, made with an insulin needle, the cannula can be inserted oriented 90 degrees with the incision; USG probe positioning can be made focusing just above the incision, with the tip of the probe slightly turned towards the incision; USG image shows, from anterior to posterior, skin, subcutaneous tissue and maxillary bone periosteum. The infraorbitary foramen can be visualized as a continuity fail in the periosteum, where the infraorbitary nerve arises from. Anesthetic solution injection can be visualized as a rising hypoechogenic structure pushing the surroundings from posterior to anterior, and the cannula can be visualized as a hyperechogenic structure. The angulation that the cannula can be inserted at this point may vary from 90 to 180 degrees, depending on hand angulation and USG visualization, in order to acquire adequate visualization. At this site, 0.5 to 1.5 $\mathrm{mL}$ can be infused (Figure 1 and Figure 2).

Patients were kept in Richmond Agitation-Sedation Score (RASS) 0 during the procedure. Additional propofol bolus was administrated in case of RASS $>0$, and sufentanyl or anesthetic solution in case of pain complaints. Cephalothin $2 \mathrm{~g}$ and omeprazole $40 \mathrm{mg}$ were administrated intravenously 15 minutes prior to main incision. Post-operative nausea and vomiting (PONV) prophylaxis was given with ondansetron and dexamethasone, and the main hydration regimen was $500 \mathrm{~mL}$ crystalloids. Analgesic prescription for postoperative period as "if necessary" was oral ketorolac $10 \mathrm{mg}$ single dose.

Hospitalar discharge happened when the patients were fully alert, hemodynamically stable with post-anesthetic scale score of 09 or above.

\section{Results}

From the initially 242 surgical prontuaries in both institutions, 218 made it to the eligibility criteria. As exposed in Table 1, the majority of patients belonged to the feminine gender, with the average age of 62 years. Every patient received 

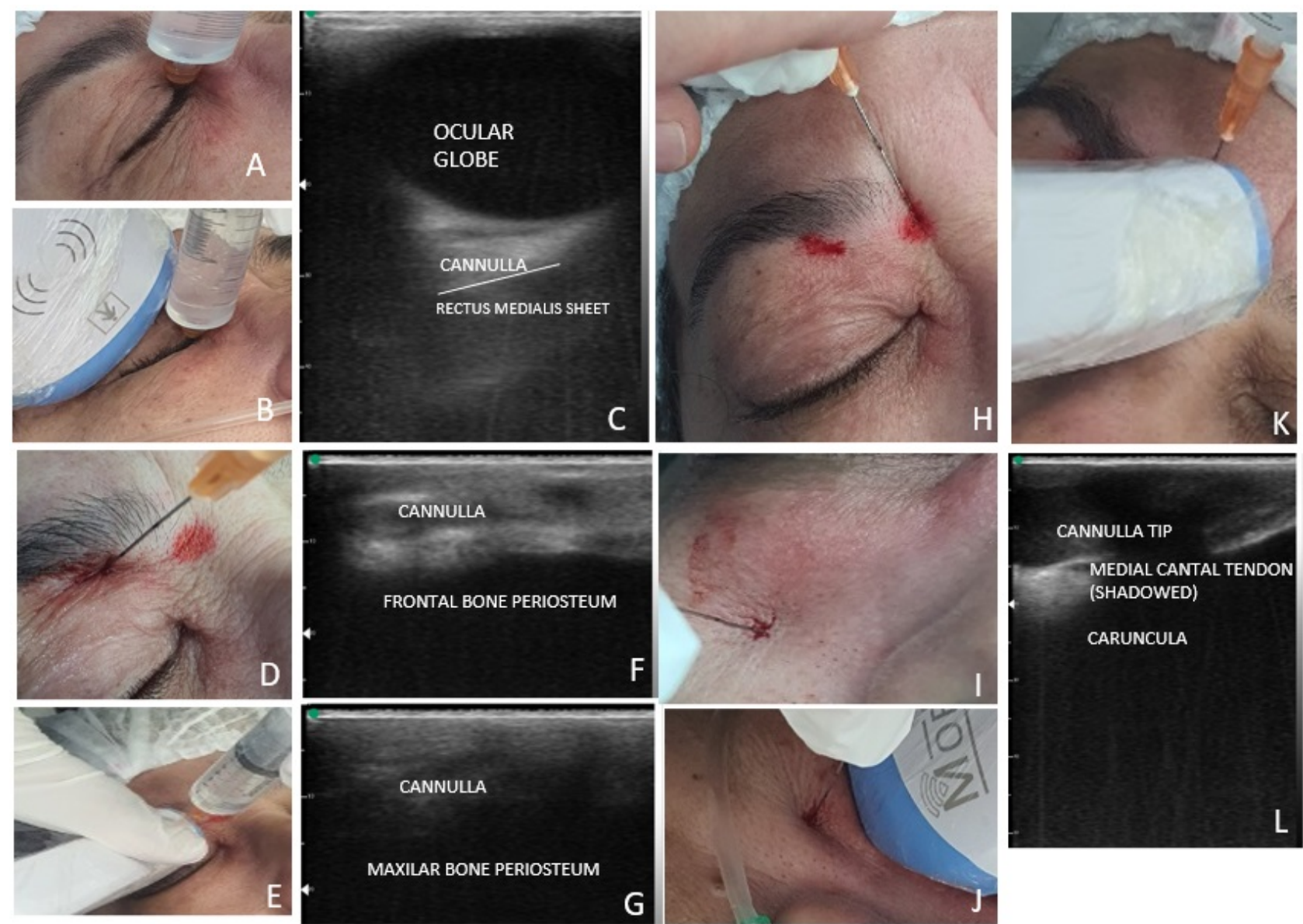

Figure 1. (A)-(C) are for Nasociliary blockage. (A) Cannula insertion; (B) Positioning of USG probe (ocular transversal nine hour cut); (C) USG image. (D)-(F) are for supraorbitary blockage. (D) Cannula positioning; (E) USG probe positioning; (F) USG image. $(\mathrm{H})-(\mathrm{L})$ are for supratrochlear and infratrochlear nerves blockage. $(\mathrm{H})$ Cannula injection site; (K) USG probe positioning towards the medial cantal tendon; (L) USG image. (G)-(J) are for infraorbitary blockage. (G) Cannula positioning; (I) USG probe positioning can be made focusing just above the incision, with the tip of the probe slightly turned towards the incision; (J) USG image.
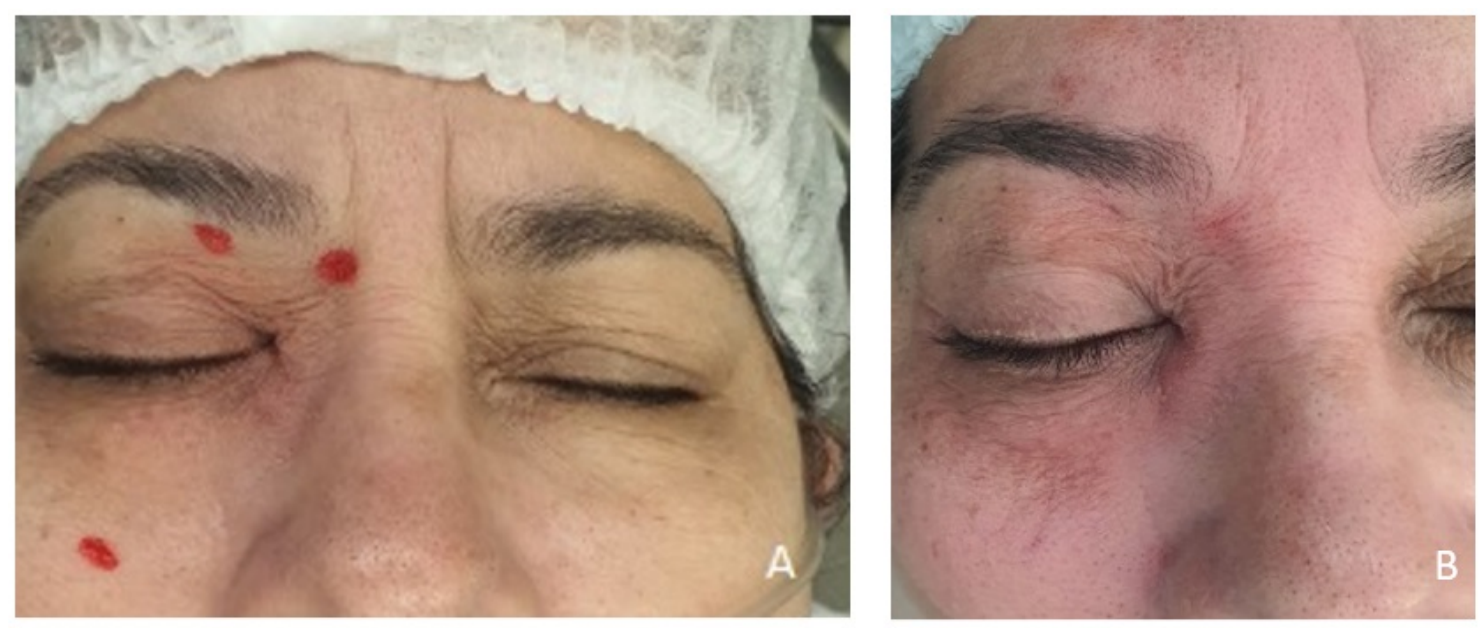

Figure 2. (A) An hydrophilic pen utilized to identify surface anatomy marks, from superior to inferior, supraorbitary notch, supero-medial orbitary angle and infraorbitary foramen; (B) Main final aspect after the blockage. 
Table 1. Analytical data

\begin{tabular}{cc}
\hline Gender (Male/Female) & $42 / 176(19 / 81 \%)$ \\
Age (mean) & 62 \\
IAV (mean, mil) & 7 \\
FAV (mean, mil) & 8.4 \\
SS (yes/no) & $14(6.4 \%)$ \\
AC1 & $3(1.3 \%)$ \\
AC2 & $1(0.4 \%)$ \\
AC3 & 0 \\
AC4 & 0 \\
HD (mean, minutes) & 35 \\
\hline
\end{tabular}

Analytical data extracted from surgical prontuaries of both institutions. Gender Male vs Female (42 vs 176); mean of age, mean of initial anesthetic volume (IAV) in milliliters; mean of final anesthetic volume (FAV) in milliliters; number of patients requiring supplementary sedation (SS); SPA is the number of patients that have had partial or complete blockage failure requiring supplementary pre-surgical anesthetic infusion in any given nerve territory before clearance to begin surgery; SSA is the number of patients that, regardless anesthetic clearance still required supplementary anesthetic field infiltration in any moment during the surgery; $\mathrm{ACl}$ is number of patients that had consumed any systemic analgesic in the immediate post operative period; AC2 is number of patients that had consumed any systemic analgesic in the first $24 \mathrm{~h}$ post operative period after hospitallary discharge; AC3 is number of patients that had consumed any systemic analgesic from the second to seventh day of post operative period; AC4 is number of patients that had consumed any systemic analgesic from the $8^{\text {th }}$ to the $30^{\text {th }}$ day post operative period; $\mathrm{HD}$ is the mean time in minutes required to hospitallary discharge.

an initial total anesthetic solution bolus of $7 \mathrm{~mL}$ and, immediately after the blockage, patients were accessed about loss of thermal sensibility in the corresponding dermatome. It was considered partial or complete anesthetic fail when thermal sensibility persisted in one given region. In that cases, additional anesthetic bolus ( $50 \%$ of anterior dose) were injected in the same territory, with the same technique, and the patient was evaluated again. When all the territories presented with loss of thermal sensibility, the surgery was cleared to begin. 29 (13\%) patients required supplementary anesthetic volume infusion prior to clearance for surgery, but $04(1.8 \%)$ presented with the complaint of pain or discomfort during nasolacrimal duct scarification and 2 (0.9\%), during posterior wall of the lacrimal sac resection, solved with surgical field anesthetic infiltration. There was no necessity for RASS bellow 0 . Supplementary analgesic or sedatives were necessary in 14 (6.4\%) patients, half of them during osteotomy, when the main complaint was "awareness of the breaking of the bone", solved with propofol bolus infusion. 11 patients $(5.0 \%)$ referred pain or discomfort during the bicanalicular silicone intubation, considered to be due to mispositioning of the intranasal gauze, solved by sufentanyl bolus. Every surgery was performed in a outpatient fashion and the average time needed to hospitalar discharge since the end 
of the procedure was $35 \mathrm{~min} .23$ patients referred mild PONV, responding to bromopride, $10 \mathrm{mg}$, single dose treatment. The outcome was positive, as postoperative analgesic consumption, intra-operative supplementary sedatives, analgesics or anesthetics and the number and quality of side effects were considered low, with a consequential high main overall satisfaction. During the follow up, 03 of the 212 patients required single dose analgesic for post operative nasal mucosa pain control in the immediate postoperative period, with 01 persisting in the first 24 hours, and no patient referred analgesic consumption in the $7^{\text {th }}$ and in the $30^{\text {th }}$ post operative day (Table 1 and Table 2 ).

\section{Discussion}

Loco-regional anesthesia is a viable technique for ED, safe to be utilized in a outpatient fashion, and promotes adequate pain control both intra and postoperative, although not free of adverse events [13]-[26]. The utilization of blunt cannula along with ultrasound guidance was associated with low anesthetic volumes and few adverse events related to this technique.

In 1991, Dresner and colleagues suggested that ED could be performed safely in an outpatient Fashion [14]. Ferda Ciftci and colleagues, compared, in 2005, the effectiveness, complications and patient acceptance of local anesthesia with general anesthesia in young patients for ED [8]. In an 8-year period, 480 procedures were performed, being 298 with local anesthesia (LA), and the researchers concluded that there was better pain and bleeding control in this group, with also higher PONV rates in the general anesthesia (GA) group. All patients had hospital admission, one disadvantage, when compared to ours, performed essentially

Table 2. Anesthetic interventions associated with each surgical steps and rate of success of each intervention.

\begin{tabular}{|c|c|c|c|}
\hline \multirow[t]{2}{*}{ Surgical step } & \multicolumn{3}{|l|}{ Data acquired } \\
\hline & Complaint (\%) & Action (\%) & Results (\%) \\
\hline Cutaneous incision & $\mathrm{N} / \mathrm{R}$ & $\mathrm{N} / \mathrm{N}$ & $\mathrm{N}$ \\
\hline Tissue dissection & $\mathrm{N} / \mathrm{R}$ & $\mathrm{N} / \mathrm{N}$ & $\mathrm{N}$ \\
\hline $\begin{array}{l}\text { Nasolacrimal groove } \\
\text { scarification }\end{array}$ & Pain. discomfort (1.8\%) & $\begin{array}{l}\text { Surgical field infiltration with } 0.3 \mathrm{~mL} \\
\text { of anesthetic mixture (100\%) }\end{array}$ & Success $(100 \%)$ \\
\hline $\begin{array}{l}\text { Posterior wall of the lacrimal } \\
\text { sac ressection }\end{array}$ & Pain. discomfort $(0.9 \%)$ & $\begin{array}{l}\text { Surgical field infiltration with } 0.3 \mathrm{~mL} \\
\text { of anesthetic mixture (100\%) }\end{array}$ & Success $(100 \%)$ \\
\hline Ostheotomy & $\begin{array}{l}\text { Discomfort/awareness } \\
(3.2 \%)\end{array}$ & $\begin{array}{l}\text { Sedation with propofol } 0.3 \mathrm{mg} / \mathrm{kg} \\
(100 \%)\end{array}$ & $\begin{array}{l}\text { Success }(85 \%) \text {. repeat previous } \\
\text { action. than success }(15 \%)\end{array}$ \\
\hline $\begin{array}{l}\text { Bicanalicullar silicone } \\
\text { intubation }\end{array}$ & $\begin{array}{l}\text { Nasal pain/discomfort } \\
(5.0 \%)\end{array}$ & $\begin{array}{l}\text { Analgesia with sufentanyl } 0.03 \mathrm{mg} / \mathrm{kg} \\
(100 \%)\end{array}$ & $\begin{array}{l}\text { Success }(10 \%) \text {. repeat previous } \\
\text { action. than success }(90 \%)\end{array}$ \\
\hline Deep tissue closure & $\mathrm{N} / \mathrm{R}$ & $\mathrm{N} / \mathrm{N}$ & $\mathrm{N}$ \\
\hline Skin and muscle closure & $\mathrm{N} / \mathrm{R}$ & $\mathrm{N} / \mathrm{N}$ & $\mathrm{N}$ \\
\hline Nasal fixation of the silicone & $\mathrm{N} / \mathrm{R}$ & $\mathrm{N} / \mathrm{N}$ & $\mathrm{N}$ \\
\hline
\end{tabular}

Success was defined as resolution of patients' complaints. 
in an outpatient fashion. Although the nerve territories utilized to perform the blocks were different, their outcomes were similar to this study, but with a homogenic population, instead of a heterogenic one. McNab and colleagues, in 2002, had stablished the effectiveness of LA for ED, with similar findings, although, with the combination of sedation for comfort improvement. In our findings, the rate of supplementary LA infiltration was due to abscess, which can rise the local anesthetic requirements, besides loss of thermal sensation in the corresponding dermatome before clearance to surgery [10]. Supplementary sedation was also necessary in our study for anxiety due to awareness of the surgical step. As Ciftci concluded, adequate nerve block, with enough volume, could ensure high quality procedure, with an aware, satisfied patient. Although, the presence of an anxious patient and abscess brings the necessity to individualize patients care, these conclusions were also made in the study from Tawfik, in 2013, where it was necessary heavy sedation in 08 uncooperative patients, and supplementary LA in 04 patients for intolerable pain.

Chaume, in 2010, stablished four nerve territories, in a study with 34 patients, with $88.4 \%$ of the patients declaring were ready to choose the same anesthetic protocol if new surgery was needed. The nerve territories utilized were almost the same as in this study, and the researchers discussed also that there are few studies focused in discuss ED under local anesthesia and sedation [11].

Sagiv and colleagues, in 2015 compared GA with LA, but this study also included an endoscopic approach, with similar surgical success rate between them, but with a higher success rate within the GA group [19].

Regarding the individual blockage procedure of each nerve territory, the utilization of a blunt cannula was considered easy and safe by the investigators with no adverse events associated. USG promoted better visualization of anatomical landmarks and the deposition of anesthetic volume, providing adequate anesthesia, with average anesthetic volume similar to the study from Ciftci, but lower than the others.

The surgical steps when patients referred pain or discomfort, were considered mild, tolerable and treatable by the team and the patients. Nasal mucosal discomfort accounted for $100 \%$ of patients' analgesic consumption in the postoperative period. Analgesic consumption was considered low, as there was no patient referred consuming more than the one dose only prescribed as "if necessary".

\section{Limitations of the Study}

As a retrospective descriptive case series, with only one exposure factor, no comparison was performed, consequentially, it was not possible to statistically determine the influence of the intervention in the outcome.

\section{Conclusion}

Although this research is a case series, with inherent limitations, such as low generalization, and biases associated to this model, it enlightens hypothesis formu- 
lations. This manuscript was important to the better knowledge of the anatomy of the face and the adjustment for reproducibility of the anesthetic technique. It is still necessary bigger studies in order to allow better understanding of the process, and thus even more efficient approach.

\section{Acknowledgements}

CEPOA is an institution specialized in the eye care, acting in the city of Rio de Janeiro, RJ, Brazil, for more than 60 years, with vocation for education, certified by the Brazilian Council of Ophthalmology as a center for specialization in Ophthalmology and sub specialization in Oculoplastics, among other subspecialities, having approximately 250 surgeries/month, between public service and private setting patients. The HO Julio Candido de Brito is a public ophthalmologic specialized service in the city of Duque de Caxias, RJ, Brazil, with a wide populational range, performing over 1.200 surgeries/month. In this hospital, it was possible to bring public, free access, eyecare to people from the whole country, accounting over 3.5 million consultations since its begin, in December 2017, among general ophthalmologic consultation, cataract surgery, oculoplastics, glaucoma, cornea, posterior segment and strabismus. Without the contribution of all personnel involved and patients that seek for assistance, this data could not be generated.

\section{Conflicts of Interest}

The authors declare no conflicts of interest regarding the publication of this paper.

\section{References}

[1] Sobel, R.K., Aakalu, V.K., Wladis, E.J., Bilyk, J.R., Yen, M.T. and Mawn, L.A. (2019) A Comparison of Endonasal Dacryocystorhinostomy and External Dacryocystorhinostomy: A Report by the American Academy of Ophthalmology. Review Ophthalmology, 126, 1580-1585. https://doi.org/10.1016/j.ophtha.2019.06.009

[2] Toti, A. (1904) Nuovo metodo conservatore di cura radicle delle suppurazoni croniche del sacco lacrimale (Dacriocistorinostomia). Clinica Moderna Firenze, 10, 385 387.

[3] Dupuy-Dutemps, B. (1921) Procede plastique de dacryocystorhinostomie et ses resultants. Annales d Ocullstique, 158, 241-261.

[4] Thompson, C.J. (2001) Review of the Diagnosis and Management of Acquired Nasolacrimal Duct Obstruction. Optometry, 72, 103-111.

[5] Dortzbach, R.K. (1978) Dacryocystorhinostomy. Ophthalmology, 85, 1267-1270. https://doi.org/10.1016/S0161-6420(78)35557-3

[6] Jawaheer, L., MacEwen, C.J. and Anijeet, D. (2017) Endonasal versus External Dacryocystorhinostomy for Nasolacrimal Duct Obstruction. Cochrane Database of Systematic Reviews, 2, CD007097. https://doi.org/10.1002/14651858.CD007097.pub3

[7] Feng, Y.F., Cai, J.Q., Zhang, J.Y. and Han, X.H. (2011) A Meta-Analysis of Primary Dacryocystorhinostomy with and without Silicone Intubation. Canadian Journal of Ophthalmology, 46, 521-527. https://doi.org/10.1016/j.jcjo.2011.09.008 
[8] Ciftci, F., Pocan, S., Karadayi, K. and Gulecek, O. (2005) Local versus General Anesthesia for External Dacryocystorhinostomy in Young Patients. Ophthalmic Plastic Reconstructive Surgery, 21, 201-206. https://doi.org/10.1097/01.IOP.0000163317.73873.C9

[9] Caesar, R.H. and McNab, A.A. (2004) External Dacryocystorhinostomy and Local Anesthesia: Technique to Measure Minimized Blood Loss. Ophthalmic Plastic Reconstructive Surgery, 20, 57-59. https://doi.org/10.1097/01.IOP.0000105567.09310.7C

[10] McNab, A.A. and Simmie, R.J. (2002) Effectiveness of Local Anesthesia for External Dacryocystorhinostomy. Clinical Experience Ophthalmology, 30, 270-272. https://doi.org/10.1046/j.1442-9071.2002.00535.x

[11] Chaume, A., Maalouf, T., Thirion, B., Angioi, K. and George, J.L. (2010) External Dacryocystorhinostomy under Local Anesthesia and Sedation. Journal Français d Ophthalmologie, 33, 77-83. https://doi.org/10.1016/j.jfo.2009.12.007

[12] Standring, S. (2020) Gray's Anatomy, 42nd Edition. The Anatomical Basis of Clinical Practice. Elsevier, Amsterdam.

[13] Benatar-Haserfaty, J., Monleon de la Calle, M.P., Sanz-Lopes, A. and Muriel Garcia, A. (2007) Outpatient External Dacryocystorhinostomy under Regional Anesthesia and Sedation. Revista Española de Anestesiologia e Reanimacion, 54, 23-28.

[14] Dresner, S.C., Klussman, K.G., Meyer, D.R. and Linberg, J.V. (1991) Outpatient Dacryocystorhinostomy. Ophthalmic Surgery, 22, 222-224.

https://doi.org/10.3928/1542-8877-19910401-12

[15] Jordan, D.R. (1991) Avoiding Blood Loss in Outpatient Dacryocystorhinostomy. Ophthalmic Plastic Reconstructive Surgery, 7, 261-266. https://doi.org/10.1097/00002341-199112000-00005

[16] Rodriguez Navarro, M.A., Perez Moreno, J.A., Padilla Rodriguez, J., Cantos Gomez, E., Sanz Campillo, J. and Marti-Ascanio, N. (2000) Use of EMLA Cream and Ropivacaine in Dacryocystorhinostomy with Locoregional Anesthesia and Sedation. Revista Española de Anestesiologia e Reanimacion, 47, 252-255.

[17] Kratky, V., Hurwitz, J.J., Ananthanarayan, C. and Avram, D.R. (1994) Dacryocystorhinostomy in Elderly Patients: Regional Anesthesia without Cocaine. Canadian Journal of Ophthalmology, 29, 13-16. https://doi.org/10.1097/00002341-199503000-00029

[18] Dumas, G.A., Bryant, A.S., Ibey, J., Long, J.A., Vicinanzo, M.G. and Boyd, G.L. (2018) Safety Comparison of Laryngeal Mask Use with Endotracheal Intubation in Patients Undergoing Dacryocystorhinostomy Surgery. Ophthalmic Plastic Reconstructive Surgery, 34, 324-328. https://doi.org/10.1097/IOP.0000000000000969

[19] Sagiv, O., Rosen, N., Priel, A., Rosner, M. and Ben Simon, G.J. (2015) Dacryocystorhinostomy (DCR) under Local Anesthesia. Harefuah, 154, 110-113.

[20] Tawfik, H.A. and Youssef, O.R. (2013) Simplified Local Anesthesia Technique for External Dacryocystorhinostmy without Nasal Packing: A New Technique and Pilot Study Outcome. Clinic Ophthalmology, 7, 2265-2270. https://doi.org/10.2147/OPTH.S53626

[21] Knezevic, M.M., Vlajkovic, G.P., Stojkovic, M.Z., Rasic, D.M., Stankovic, B.R. and Bozic, M.M. (2012) Comparison of Postoperative Pain and Satisfaction after Dacryocystorhinostomy in Patients Operated on under Local and General Anesthesia. Medical Science Monitor, 18, CR265-CR270.

[22] Knezevic, M.M., Stojkovic, M.Z., Vlajkovic, G.P., Jovanovic, M.B. and Rasic, D.M. (2011) Pain during External Dacryocystorhinostmy with Local Anesthesia. Medical 
Science Monitor, 17, CR341-CR346. https://doi.org/10.12659/MSM.881807

[23] Maheshwari, R. (2008) Single-Prick Infiltration Anesthesia for External Dacryocystorhinostomy. Orbit, 27, 79-82. https://doi.org/10.1080/01676830701377229

[24] Harissi-Dagher, M., Boulos, P., Hardy, I. and Guay, J. (2008) Comparison of Anesthetic and Surgical Outcomes of Dacryocystorhinostomy Using Loco-Regional versus General Anesthesia. Digital Journal of Ophthalmology, 14, 1-6. https://doi.org/10.5693/djo.01.2008.001

[25] Aldrete, J.A. and Kroulik, D. (1970) A Postanesthetic Recovery Score. Anesthesia and Analgesia, 49, 924. https://doi.org/10.1213/00000539-197011000-00020

[26] Palumbo, P., Tellan, G., Perotti, B., Pacile, M.A., Vietri, F. and Illuminati, G. (2012) Modified PADSS (Post Anaesthetic Discharge Scoring System) for Monitoring Outpatients Discharge. Annali Italiani di Chirurgia, 84, 661-665. 